\title{
The Relationship of Age, Parity and Body Mass Index as Risk Factors to the Incidence of Uterine Myoma in Dr. Hasan Sadikin General Hospital
}

\author{
Nurul Ilma, ${ }^{1}$ Dian Tjahyadi, ${ }^{2}$ Tina Dewi Judistiani ${ }^{3}$ \\ ${ }^{1}$ Faculty of Medicine, Universitas Padjadjaran, ${ }^{2}$ Department of Obstetric and Gynaecology, Faculty \\ of Medicine, Universitas Padjadjaran/Dr. Hasan Sadikin General Hospital, Bandung, ${ }^{3}$ Department \\ of Epidemiology and Biostatistics, Faculty of Medicine, Universitas Padjadjaran
}

\begin{abstract}
Background: Uterine myoma is a benign gynecological tumor which is commonly occurred in women. The incidence of uterine myoma in the world is $20-35 \%$ while in Indonesia is about $2.4-11.7 \%$. Age, parity, and body mass index are correlated with the incidence of uterine myoma. This study aimed to determine the relationship among those factors towards uterine myoma, and to identify the prognostic value of body mass index in order to prevent uterine myoma.

Methods: A case-control study was conducted to examine 394 medical records of patients with uterine myoma at Department of Obstetrics and Gynecology Dr. Hasan Sadikin General Hospital Bandung from 2006 to 2011. The case group were 133 and the control group were 261. The data were the subject's weight, height, age, and parity. The correlation among all variable and the occurrence of uterine myomas were conducted using multiple logistic regression analysis.

Results: There was no different range of age between the two groups. The incidence rate ratio of parity was 2.254 (95\% confidence interval:1.310-3.876), followed by body mass index $>33.0$ incidence rate ratio was 1.691 (95\% confidence interval: 0.477-5.994). From the receiver operating characteristic curve, it could be seen that the cut-off points for body mass index was $20.44 \mathrm{~kg} / \mathrm{m}^{2}$, and the risk of uterine myomas scaled up as the increase of body mass index.

Conclusions: Parity and BMI can affect the risk of uterine myomas. To prevent the incident of uterine myomas, parity must be limited and BMI must be below the cut-off points $\left(20.44 \mathrm{~kg} / \mathrm{m}^{2}\right)$. [AMJ.2015;2(3):409-13]
\end{abstract}

Keywords: Body mass index, uterine myoma, parity

\section{Introduction}

Uterine myomas are benign tumors which most commonly struck women during their reproductive years. ${ }^{1,2}$ Uterine myomas can cause several symptoms; the most common of which are dysmenorrhea and menorrhagia. ${ }^{3-5}$

The incidence of uterine myomas around the world is $20-35 \%$ while in Indonesia the incidence of myoma is about $2.4-11.7 \%$. In contrast to the data, in Dr. Hasan Sadikin General Hospital uterine myoma has become the most common gynecological tumor; the hospital annual report notes that the incidence of uterine myoma is about 6.43-12.46\%.

The incidence of uterine myomas increases in black women., ${ }^{1,8}$ It possibly occurred since black women are usually women with exposure of oral contraceptives. ${ }^{1,7}$ The incidence also increases in women who have the history of uterine myomas in their family. ${ }^{1,8}$ The risk of uterine myoma also increases in nuliparous and overweight women. ${ }^{1}$ The impact of uterine myomas including dysmenorrhea and menorrhagia can lead the victims to anemia, pelvic pain, infertility, and pregnancy complications like miscarriage, abnormal insertion of placenta (placenta previa and placenta acreta), premature labour, and postpartum hemorrhage. ${ }^{1,3,7}$ In addition, uterine myoma also can cause urinary symptoms. ${ }^{1,3}$

The changes of Body Mass Index (BMI) influence the incidence of uterine myomas. In

Correspondence: Nurul Ilma, Faculty of Medicine, Universitas Padjadjaran, Jalan Raya Bandung-Sumedang Km.21, Jatinangor, Sumedang, Indonesia, Phone: +628567743088 Email: nurul.ilma@yahoo.com 
obese patients, the risk of myoma increases to 2.7 times greater than the patients with normal BMI. $^{7}$ Besides multiple factors in the growth of myoma have been mentioned, like reproductive hormone and race,1,3,7,8 there are other factors in the growth of myoma, namely: family history, lifestyle, and environmental condition..$^{1,3}$ Uterine myomas are closely associated with estrogen stimulation, especially where there is abundant peripheral conversion of androgen to estrogen in obese patients. $1,9,10$

In a study by Wise et al. ${ }^{11}$, it was stated that there is a relationship between the incidence of uterine myomas with body mass index obesity (with Odds Ratio [OR] 1.36, 95\% Confidence Interval [CI] 1.02-1.80) in the United States. In addition, Vanessa et al. ${ }^{12}$, in their study stated that for black woman who had BMI exceeding the normal value had a risk of uterine myomas nearly 3 times (with OR 2.7; 95\% CI 2.3-3.2). Moreover, in a study conducted by Shikora et al. ${ }^{13}$, it was stated that most of the patients with uterine myoma had obese BMI, and there even is a subject with severe obese BMI.

So far, the researcher has not found a study which focuses on finding the cut-off point of $\mathrm{BMI}$ and its prognostic value to prevent uterine myomas in Indonesian population. This study can be considered as a pilot study.

\section{Methods}

A case-control study was conducted among patients with uterine myomas at the Department of Obstetrics and Gynecology Dr. Hasan Sadikin General Hospital Bandung from 2006 to 2011. The weight, height, age and parity of the subjects were collected from medical records.

The case was defined based on histopathological examination results of specimen, and as for controls were selected non-myoma subjects hospitalized during the same period. Excluded were all gynecologic in-patients subjects with diabetes mellitus, Cushing's syndrome, hypothyroidism, pregnancy and patients with incomplete records. As much as 133 cases and 261 controls were taken for analysis.

The descriptive analysis about the characteristics of the subjects was performed by cross tabulation analysis (Table 1). The analysis of the correlations between all variables and the occurrence of uterine myomas were performed by multiple logistic

Table 1 Characteristic of the Case and Control Groups

\begin{tabular}{|c|c|c|c|}
\hline \multirow{2}{*}{ Variable } & Case & Control & \multirow{2}{*}{ P Value } \\
\hline & $\mathrm{N}=133(\%)$ & $N=261(\%)$ & \\
\hline Age (years) & & & 0.09 \\
\hline $20-30$ & $7(5.26 \%)$ & $28(9.96 \%)$ & \\
\hline $30-40$ & $43(32.3 \%)$ & 95 (35.25\%) & \\
\hline$>40$ & $83(62.54 \%)$ & $138(54.79 \%)$ & \\
\hline Infertility & $36(27.1 \%)$ & $45(17.24 \%)$ & $0.021^{*}$ \\
\hline \multicolumn{4}{|l|}{ Parity $\geq 1$} \\
\hline Primiparous & $25(18.79 \%)$ & $38(14.56 \%)$ & 0.068 \\
\hline Multiparous & & & $0.004^{*}$ \\
\hline$<4$ & $55(41.35 \%)$ & $96(36.78 \%)$ & \\
\hline$\geq 4$ & 17 (12.78\%) & $82(31.42 \%)$ & \\
\hline Body Mass Index & & & $0.003^{*}$ \\
\hline$<19$ & $7(5.26 \%)$ & $46(17.63 \%)$ & \\
\hline $19-23.6$ & $53(39.84 \%)$ & $111(42.53 \%)$ & \\
\hline $23.7-28.3$ & $50(37.60 \%)$ & $74(28.35 \%)$ & \\
\hline $28.4-33.0$ & $19(14.29 \%)$ & $20(7.66 \%)$ & \\
\hline$>33.0$ & $4(3.01 \%)$ & $10(3.83 \%)$ & \\
\hline
\end{tabular}


Nurul Ilma, Dian Tjahyadi, Tina Dewi Judistiani: The Relationship of Age, Parity and Body Mass Index as Risk 411 Factors to the Incidence of Uterine Myoma in Dr. Hasan Sadikin General Hospital

Table 2 Multivariate Analysis with the Incidence of Uterine Myomas

\begin{tabular}{|c|c|c|c|}
\hline Variable & P Value & Odd Ratio & $\begin{array}{c}\text { 95\% Confidence } \\
\text { Interval }\end{array}$ \\
\hline \multicolumn{4}{|l|}{ Age (years) } \\
\hline $20-30$ & Comparison & & \\
\hline $30-40$ & $0.032^{*}$ & 0.364 & $0.144-0.919$ \\
\hline$>40$ & 0.133 & 0.690 & $0.425-1.119$ \\
\hline \multicolumn{4}{|l|}{ Parity } \\
\hline Nuliparous & Comparison & & \\
\hline Parity $\geq 1$ & $0.003^{*}$ & 2.254 & $1.310-3.876$ \\
\hline \multicolumn{4}{|l|}{ Body Mass Index } \\
\hline$<19$ & Comparison & & \\
\hline $19-23.6$ & 0.065 & 0.280 & $0.072-1.081$ \\
\hline $23.7-28.3$ & 0.851 & 0.897 & $0.288-2.793$ \\
\hline $28.4-33.0$ & 0.758 & 1.198 & $0.381-3.766$ \\
\hline$>33.0$ & 0.416 & 1.691 & $0.477-5.994$ \\
\hline
\end{tabular}

regression analysis (Table 2). The analysis of the correlation between BMI and myoma uteri was performed by cross-tabulation analysis (Table 3), and the analysis of cut-off points was performed by the receiver operating characteristic curve analysis (Figure 1).

\section{Result}

Table 1 shows the distribution frequencies of study subjects' characteristic between the case and the control groups. The percentage of subjects who obtained the highest incidence of uterine myomas are those women aged above 40 years at $56.10 \%$, followed by woman in age group of $30-40$ years at $35.03 \%$, and the latter age group of 20-30 years at $8.88 \%$. Table 1 also shows that maternal age variable with a value of $p=0.090$; it indicated that there was no difference between the case and the control groups on the incidence of myomas uteri in this study. Thus, it can be concluded that the subjects' age variable of the study were comparable.

Based on the Table 1, for infertile variable, subjects mostly came from the control group with $p$ value 0.021 . Several other factors can influence infertility, not only uterine myomas.

There was no difference between primiparous and multiparous subjects. However, there was a significant difference between parity $<4$ group and parity $\geq 4$ $(p=0.004)$. This can be explained by the repeated exposure to estrogen which can trigger the growth of the tumor, and also in multiparous subjects the tumor usually lies in non-vital areas in pregnancy.

In addition, to age and parity, subjects

Table 3 Relationship between Nutritional Status with Myomas Uteri

\begin{tabular}{|c|c|c|c|c|c|c|}
\hline \multirow{2}{*}{ Characteristic } & \multicolumn{2}{|c|}{ Uterine myomas } & \multirow{2}{*}{ P Value } & \multirow{2}{*}{ OR } & \multirow{2}{*}{$95 \% \mathrm{CI}$} & \multirow{2}{*}{$\begin{array}{c}\text { Likelihooc } \\
\text { Ratio }\end{array}$} \\
\hline & Yes & No & & & & \\
\hline $\begin{array}{l}\text { Body mass index } \\
\left(\mathrm{kg} / \mathrm{m}^{2}\right)\end{array}$ & & & 0,003 & & & \\
\hline$<19$ & 7 & 46 & & & Comparison & \\
\hline $19-23.6$ & 53 & 111 & & 3.138 & $1.328-7.414$ & 8.130 \\
\hline $23.7-28.3$ & 50 & 74 & & 4.440 & $1.856-10.623$ & 13.852 \\
\hline $28.4-33.0$ & 19 & 20 & & 5.914 & $2.135-16.380$ & 13.051 \\
\hline$>33.0$ & 4 & 10 & & 3.286 & $0.864-12.497$ & 2.907 \\
\hline
\end{tabular}




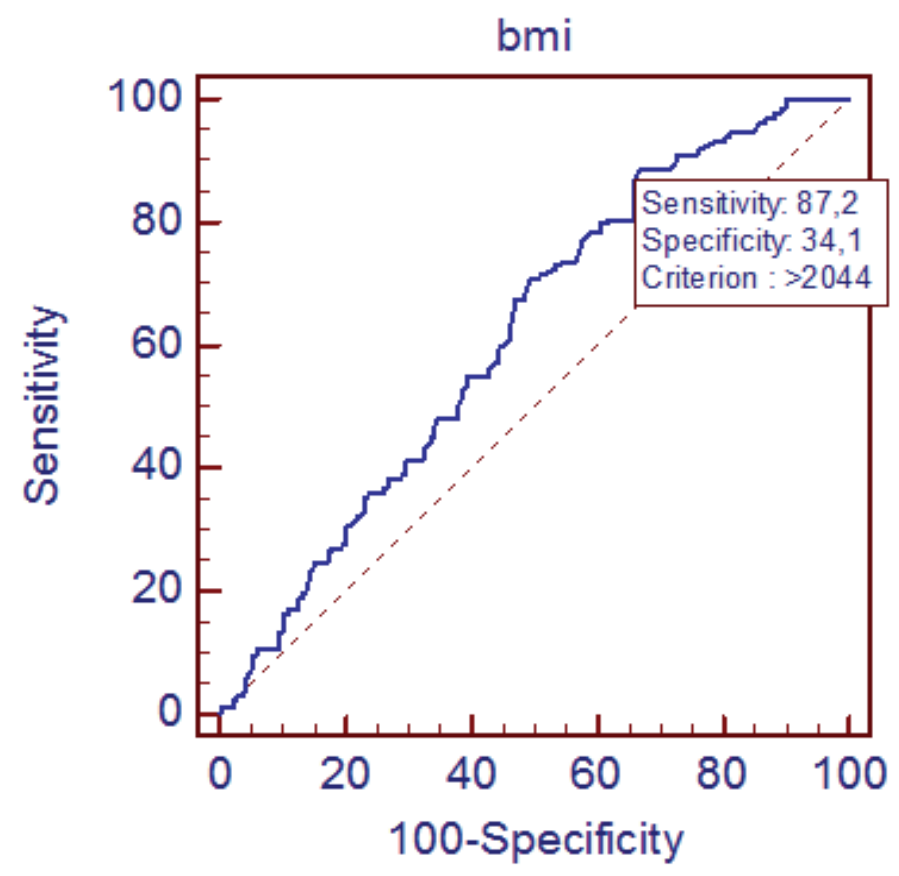

Figure Receiver Operating Characteristic (ROC) curve

mostly came with BMI 19-23.6 (41.62\%) as is shown in Table 1 . For BMI $p=0.003$, it showed significant difference between the nutritional status in the case and the control groups on the risk of uterine myomas.

The multivariate logistic regression analysis from multivariate Incidence Rate Ratio [IRR] showed the highest risk of uterine myoma came from subjects with parity $\geq 1$, the risk was 2.254 times greater than subjects in nuliparous group (OR 2.254, 95\% CI 1.3103.876). This result is similar to a study by Wise et al. ${ }^{14}$ who stated that the incidence of uterine myomas is higher in multiparous group (OR 1.6; 95\% CI 1.0-2.0).

The highest risk for BMI variable came from subjects with BMI >33.0 (IRR 1.691; 95\% CI 0.477-5.994) and was followed by subjects with BMI 28.4-33.0 (IRR 1.198; 95\% CI 0.3813.766).

Based on Table 3 , the risk of uterine myoma scaled up as the increase of BMI, and there was significant relationship between body mass index and the risk of uterine myomas $(\mathrm{p}=0.003)$. Subjects with BMI 28.4-33.0 and with $\mathrm{BMI}>33.0$ had greater risk than subjects with BMI $<19$.

Based on this result, cut-off points were found using receiver operating characteristic analysis; the curve is shown in Figure 1.
Cut-off points for BMI in relation to uterine myomas were $20.44 \mathrm{~kg} / \mathrm{m}^{2}$. From these cutoff points, it could be said that subjects who had BMI over $20.44 \mathrm{~kg} / \mathrm{m}^{2}$ had a greater risk of uterine myomas, and this cut-off point could be used as a baseline value to prevent the incidence of uterine myomas among women in reproductive years.

\section{Discussion}

This study is the first study aimed to determine the relationship between age, parity and BMI as a risk factor for uterine myomas in Indonesian population. The implication of result was significant as described by Wise et al. ${ }^{14}$, who stated that the incidence of uterine myomas is higher in multiparous group with risk increase (OR 1.6; 95\% CI 1.0-2.0). The study also finds that there is a correlation between BMI and uterine myomas; this result is significant as described by Wise et al. ${ }^{11}$, Vanessa et al. ${ }^{12}$ and Shikora et al. ${ }^{13}$

In this study, the cut-off points for BMI in relation to uterine myomas were $20.44 \mathrm{~kg} / \mathrm{m}^{2}$. Based on these cut-off points, the subjects, who had BMI more than the baseline, had a greater risk of uterine myomas than the subjects with BMI under the baseline. One way to prevent the incident of uterine myomas was to maintain 
BMI below the baseline $\left(20.44 \mathrm{~kg} / \mathrm{m}^{2}\right)$. So far, the researcher has not found any study which focuses on finding the cut-off points of BMI to prevent uterine myomas. Based on literature, the risk for uterine myomas increases for subjects with BMI overweight (25.0-29.9 $\left.\mathrm{kg} / \mathrm{m}^{2}\right) .{ }^{1}$ It was needed a further study to determine other risk factors related to uterine myomas.

As a conclusions, parity and BMI had influence risk of uterine myomas. To prevent the incident of uterine myomas, parity must be limited and BMI must be below the cut-off points $\left(20.44 \mathrm{~kg} / \mathrm{m}^{2}\right)$.

\section{References}

1. Stewart EA. Uterine fibroids. Lancet. 2001;357(9252):293-8.

2. Strawn EY, Novy MJ, Burry KA, Bethea CL. Insulin-like growth factor I promotes leiomyoma cell growth in fitro. Am J Obstet Gynecol. 1995;172(6):1837-44.

3. Parker WH. Etiology, symptomatology, and diagnosis of uterine myomas. Fertil Steril. 2007;87(4):725-36.

4. Wallach EE, Vlahos NF. Uterine myomas: an overview of development, clinical features, and management. Obstet Gynecol. 2004;104(2):393-6.

5. Glass RH, Curtis MG, Overholt S, Hopkins MP. Glass' office gynecology. Philadelphia: Lippincott Williams \& Wilkins; 2006. p. 178-80.

6. Wiknjosastro H. Ilmu kebidanan. $2^{\text {nd }}$ ed. Jakarta: Bina Pustaka; 2005. p. 337-45.

7. Baird DD, Dunson DB, Hill MC, Cousins D, Schectman JM. High cumulative incidence of uterine leiomyoma in black and white women: Ultrasound evidence. Am J Obstet Gynecol. 2003;188(1):100-7.

8. Stewart EA, Morton CC. The genetics of uterine leiomyomata: what clinicians need to know. Obstet Gynecol.2006;107(4):91721.

9. Berman DM, Rodrigues LM, Nicklas BJ, Ryan AS, Dennis KE, Goldberg AP. Racial disparities in metabolism, central obesity, and sex hormone-binding globulin in postmenopausal women. J Clin Endocrinol Metab. 2001;86(1):97-103.

10. Gardner DG, Shoback DM, Greenspan FS. Greenspan's Basic \& Clinical Endocrinology. New York: McGraw-Hill Medical; 2007. p. 719-23.

11. Wise LA, Palmer JR, Spiegelman D, Harlow BL, Stewart EA, Adam-Campbell LL, et al. Influence of body size and body fat distribution on risk of uterine leiomyomata in U.S. black women. Epidemiology. 2005;16(3):346-54.

12. Jacoby VL, Fujimoto VY, Giudice LC, Kuppermann M, Washington AE. Racial and ethnic disparities in benign gynecologic conditions and associated surgeries. Am J Obstet Gynecol. 2010;202 (6):514-21.

13. Shikora SA, Niloff JM, Bistrian BR, Forse RA, Blackburn GL. Relationship between obesity and uterine leiomyomata. Nutrition. 1991;7(4):251-5.

14. Wise LA, Palmer JR, Harlow BL, Spiegelman D, Stewart EA, Adams LL, et al. Reproductive factors, hormonal contraception, and risk of uterine leiomyomata in AfricanAmerican women: a prospective study. Am J Epidemiol. 2004;159(2):113-23. 